Article

\title{
Electron Backscatter Diffraction Studies on the Formation of Superlattice Metal Hydride Alloys
}

\author{
Shuli Yan ${ }^{1,2}$, Kwo-Hsiung Young ${ }^{1,2, *} \mathbb{C}^{\mathbb{D}}$, Xin Zhao ${ }^{3}$, Zhi Mei ${ }^{4}$ and K. Y. Simon $\mathrm{Ng}^{1}$ \\ 1 Department of Chemical Engineering and Materials Science, Wayne State University, Detroit, MI 48202, USA; \\ shuli.yan@partners.basf.com (S.Y.); sng@wayne.edu (K.Y.S.N.) \\ 2 BASF/Battery Materials—Ovonic, 2983 Waterview Drive, Rochester Hills, MI 48309, USA \\ 3 School of Materials and Metallurgy, Inner Mongolia University of Science and Technology, Baotou 014010, \\ Inner Mongolia, China; fatcatzx@163.com \\ 4 Department of Chemistry, Wayne State University, Detroit, MI 48202, USA; zmei@chem.wayne.edu \\ * Correspondence: kwo.young@basf.com; Tel.: +1-248-293-7000
}

Received: 2 October 2017; Accepted: 5 December 2017; Published: 13 December 2017

\begin{abstract}
Microstructures of a series of La-Mg-Ni-based superlattice metal hydride alloys produced by a novel method of interaction of a $\mathrm{LaNi}_{5}$ alloy and $\mathrm{Mg}$ vapor were studied using a combination of X-ray energy dispersive spectroscopy and electron backscatter diffraction. The conversion rate of $\mathrm{LaNi}_{5}$ increased from $86.8 \%$ into $98.2 \%$, and the $\mathrm{A}_{2} \mathrm{~B}_{7}$ phase abundance increased from 42.5 to $45.8 \mathrm{wt} \%$ and reduced to $39.2 \mathrm{wt} \%$ with the increase in process time from four to $32 \mathrm{~h}$. During the first stage of reaction, $\mathrm{Mg}$ formed discrete grains with the same orientation, which was closely related to the orientation of the host $\mathrm{LaNi}_{5}$ alloy. $\mathrm{Mg}$ then diffused through the $a b$-phase of $\mathrm{LaNi}_{5}$ and formed the $\mathrm{AB}_{2}, \mathrm{AB}_{3}$, and $\mathrm{A}_{2} \mathrm{~B}_{7}$ phases. Diffusion of $\mathrm{Mg}$ stalled at the grain boundary of the host $\mathrm{LaNi}_{5}$ alloy. Good alignments in the $c$-axis between the newly formed superlattice phases and $\mathrm{LaNi}_{5}$ were observed. The density of high-angle grain boundary decreased with the increase in process time and was an indication of lattice cracking.
\end{abstract}

Keywords: metal hydride; superlattice alloy; electron backscatter diffraction; crystallographic orientation; gaseous-state diffusion; superlattice alloy

\section{Introduction}

Rare earth (RE)/Mg-based superlattice metal hydride (MH) alloys are employed extensively in the consumer nickel/metal hydride $(\mathrm{Ni} / \mathrm{MH})$ batteries because of the following improvements over the conventional $A_{5} M H$ alloys: higher hydrogen storage capacities, better high-rate dischargeability (HRD), superior low-temperature and charge-retention performances, and improved cycle stability [1-8]. Out of the six available superlattice phases (three hexagonal and three rhombohedral), $\mathrm{Ce}_{2} \mathrm{Ni}_{7}$ was found to be the most desirable phase considering general battery performance [9], and the $\mathrm{A}_{2} \mathrm{~B}_{7}$ stoichiometry shows the best HRD, charge retention, and cycle life [10]. Although the superlattice $\mathrm{MH}$ alloys are very attractive to battery engineers, their fabrication is difficult because of the high vapor pressure of $\mathrm{Mg}$ [11] —an indispensable ingredient to maximize the capacity and stabilize the structure [12,13]. In the conventional melt-and-cast method, $\mathrm{Mg}$ was added as a late addition in the form of $\mathrm{MgNi}_{2}$ [14]. Extra $\mathrm{Mg}$ needs to be added to compensate for the loss to vapor, which is a difficult factor to control precisely. A new method of making the Mg-containing superlattice $\mathrm{MH}$ alloys [15] was proposed using a gaseous-state $\mathrm{Mg}$-diffusion into the $\mathrm{AB}_{5} \mathrm{MH}$ alloys, which can be easily produced by vacuum induction melting with a furnace size as large as one ton [16]. Early electron microscope studies indicated the feasibility of transporting $\mathrm{Mg}$ into the $\mathrm{La}_{0.8} \mathrm{Ni}_{3}$ alloy and forming the Mg-containing superlattice phases, but the constituent phases have not yet been confirmed [15]. 
Electron backscatter diffraction (EBSD) is a microstructural-crystallographic technique that allows the user to examine the crystallographic orientations of constituent phases in very localized areas (one square micron or less) of a polycrystalline material in a scanning electron microscope (SEM). Capability of EBSD can be further enhanced by including the chemical composition information gathered by X-ray energy dispersive spectroscopy (EDS) [17]. In the past, we employed EBSD in the studies of a $\mathrm{Zr}_{7} \mathrm{Ni}_{10}$ [18], a C14-based $\mathrm{AB}_{2}$ [19], and a C14/body-centered-cubic $\mathrm{MH}$ alloys [20]. In the last two cases, EBSD was used to confirm the cleanliness of the grain boundary from the strong alignment of crystallographic orientations of neighboring phases. In the current study, EBSD was used to identify the new phases formed by the Mg-diffusion into the $\mathrm{LaNi}_{5}$ alloy and study the nature of grain boundary and alignment of crystallographic orientations of neighboring phases.

\section{Experimental Setup}

The $\mathrm{LaNi}_{5}$ alloy was synthesized by induction melting La and $\mathrm{Ni}$ (both with purity higher than $99.5 \%$ ) under an argon atmosphere. Solidification of the $\mathrm{LaNi}_{5}$ alloy was operated by a rapid quenching equipment to ensure the slice thickness to be between 0.2 to $0.4 \mathrm{~mm}$. The Mg-absorption alloying process was operated in a sealed internal isolation stainless-steel retort. Slices of $\mathrm{Mg}$ and $\mathrm{LaNi}_{5}$ were placed into each side of the retort in a weight ratio of $\mathrm{Mg}: \mathrm{LaNi}_{5}=1: 30$ and separated by foraminiferous septa. The retort was placed in an annealing furnace under an inert atmosphere (argon). Annealing (reaction) temperature was increased from the ambient temperature to $1273 \mathrm{~K}$ with a heating rate of $10 \mathrm{~K} \cdot \mathrm{min}^{-1}$. Afterward, the vessel was cooled to room temperature in the furnace.

4-h, 8-h, 16-h, and 32-h annealed alloy samples were mounted in resin holders. The samples were polished using metallographic silicon carbide sandpapers in the sequence of 400-, 800- and, finally, 1200-grit (Buehler, Lake Bluff, IL, USA), and they were then finely polished with Buehler MicroPolish II Suspension 1- $\mu \mathrm{m}$ alumina suspension and PACE Technologies SIAMAT2 0.02- $\mu \mathrm{m}$ colloidal silica (PACE Technologies, Tucson, AZ, USA) to obtain a mirror finish. The prepared samples were kept in a sealed tank with high vacuum and low $\mathrm{O}_{2}{ }^{-}$and moisture content to avoid surface oxidization and physical and chemical absorptions.

To investigate the phase distribution, samples were studied by a JEOL JSM-7600 field emission SEM (JEOL USA, Inc., Peabody, MA, USA) equipped with an EDAX Pegasus Apex 2 Integrated EDS and EBSD System (EDAX Inc., Mahwah, NJ, USA). The EBSD data was collected and analyzed with TSL OIM data Collection 7 and TSL OIM Analysis 7 program (EDAX Inc., Mahwah, NJ, USA)., respectively. - All the measured points have confidence indices greater than 0.6 , which corresponds to an accuracy higher than $95 \%$. Fit parameter is the averaged angular difference between the detected and recalculated bands. In this case, the fit parameter is less than 0.8 , showing a high degree of matching.

\section{Results and Discussion}

\subsection{Phase Identification}

As stated in the Introduction, the La-Mg-Ni-type alloys were based on the La-Ni binary intermetallic alloys. The presence of $\mathrm{Mg}$ destabilizes the hydride, making it suitable for room-temperature battery applications [13]. Phases commonly reported in the La-Mg-Ni superlattice alloys are $(\mathrm{La}, \mathrm{Mg}) \mathrm{Ni}_{5},(\mathrm{La}, \mathrm{Mg})_{5} \mathrm{Ni}_{19},(\mathrm{La}, \mathrm{Mg})_{2} \mathrm{Ni}_{7},(\mathrm{La}, \mathrm{Mg}) \mathrm{Ni}_{3}$, and $(\mathrm{La}, \mathrm{Mg}) \mathrm{Ni}_{2}$. [21]. Basic subunits for these phases are the $\mathrm{AB}_{5}$ and $\mathrm{A}_{2} \mathrm{~B}_{4}$ slabs, which alternatively stack along the $c$-axis in different patterns to form the structures [21,22]. Six types of the La-Mg-Ni superlattice phases are $\operatorname{Pr}_{5} \mathrm{Co}_{19}$ (PDF: 04-004-1477), $\mathrm{Nd}_{5} \mathrm{Co}_{19}$ (PDF: 04-004-1478), $\mathrm{Ce}_{2} \mathrm{Ni}_{7}$ (PDF: 04-007-1092), $\mathrm{Pr}_{2} \mathrm{Ni}_{7}$ (PDF: 01-081-8491), $\mathrm{CeNi}_{3}$ (PDF: 04-007-1090), and $\mathrm{PuNi}_{3}$ (PDF: 04-007-1091), and their structures are either hexagonal or rhombohedral and are generally difficult to distinguish in the X-ray diffraction patterns [21-25]. Furthermore, the $\mathrm{AB}_{5}$ (PDF: 00-055-0277) and $\mathrm{AB}_{2}$ (PDF: 04-001-2137) phases are also hexagonal, which adds to the difficulty in identifying the phases. EBSD provides a powerful approach to study the lattice structures of individual phases and their alignments in certain orientations in the multi-phase 
La-Mg-Ni superlattice alloys. Figure 1 shows the crystal structures and computer-generated EBSD diffraction patterns of the (1120) planes of $\mathrm{LaNi}_{5}, \mathrm{Pr}_{5} \mathrm{Co}_{19}, \mathrm{Nd}_{5} \mathrm{Co}_{19}, \mathrm{Ce}_{2} \mathrm{Ni}_{7}, \mathrm{Pr}_{7} \mathrm{Ni}_{2}, \mathrm{CeNi}_{3}, \mathrm{PrNi}_{3}$, and $\mathrm{NbCr}_{2}$ (hexagonal), which are used as the base patterns in this study. Lattice parameters of the seven types of structures are different and, therefore, their EBSD patterns are different, especially away from the (0001) plane.
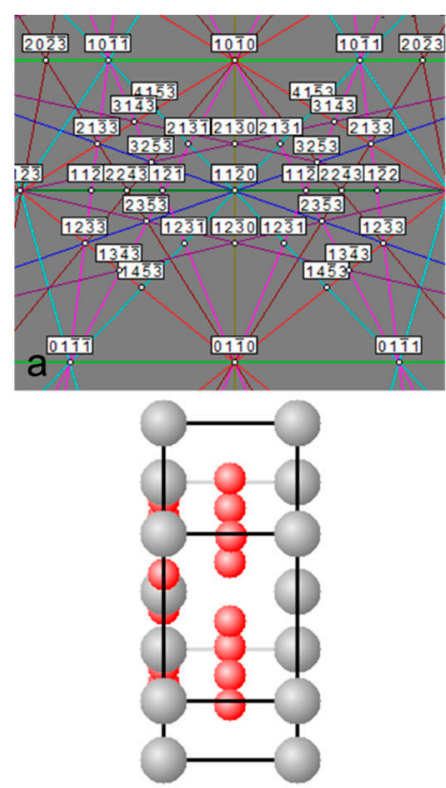

[0001]
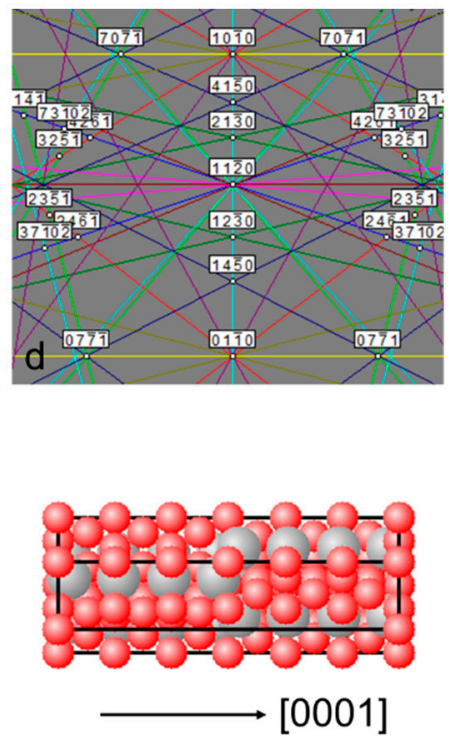
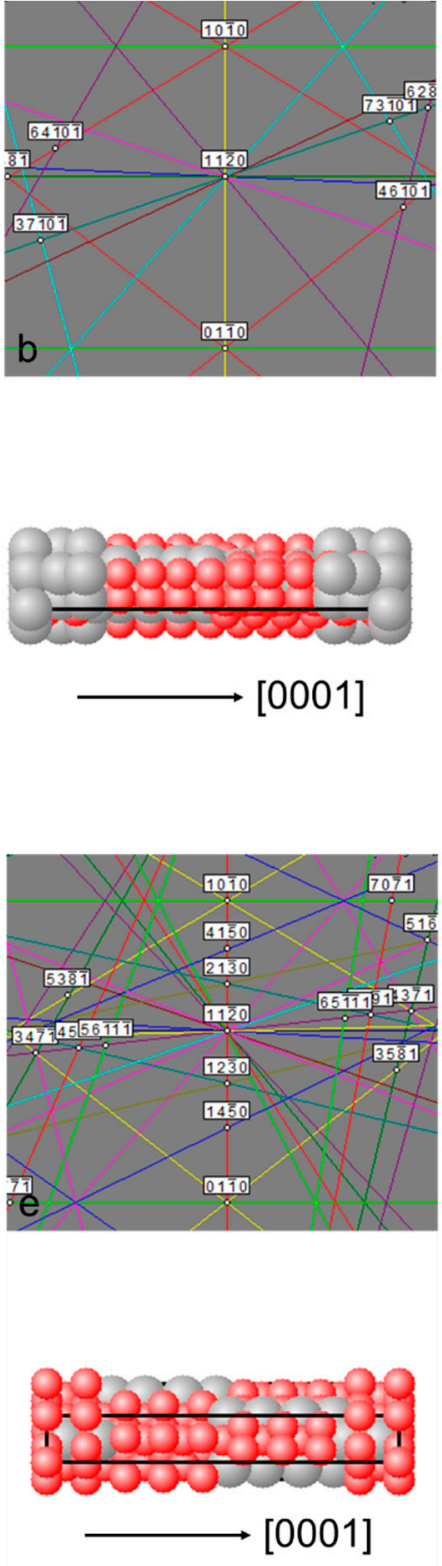
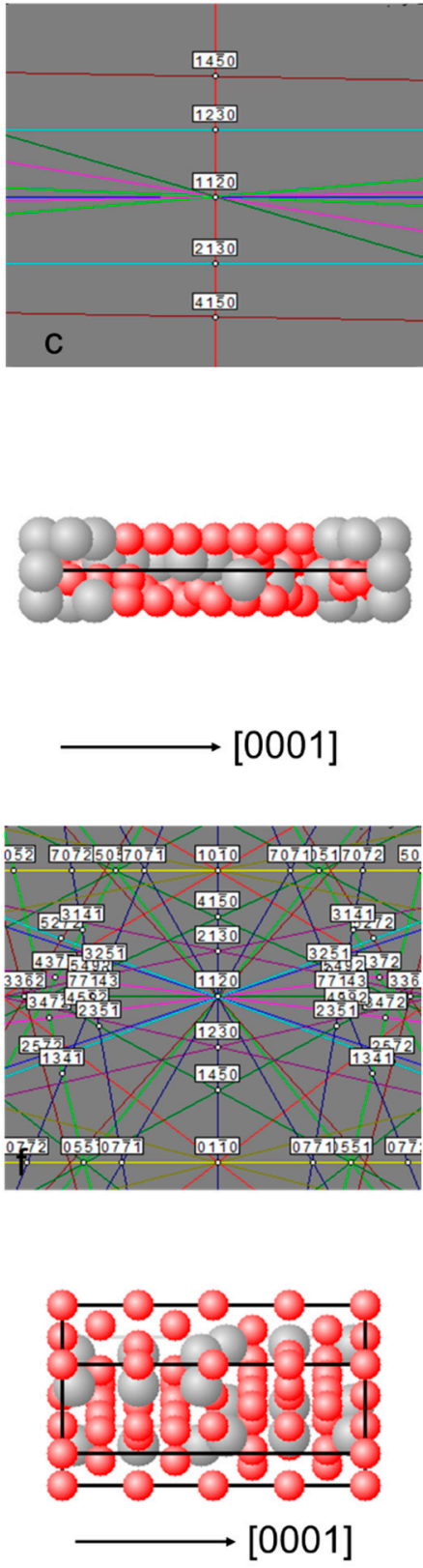

[0001]

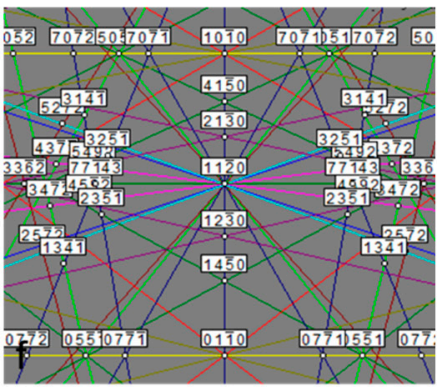

[0001]

Figure 1. Cont. 

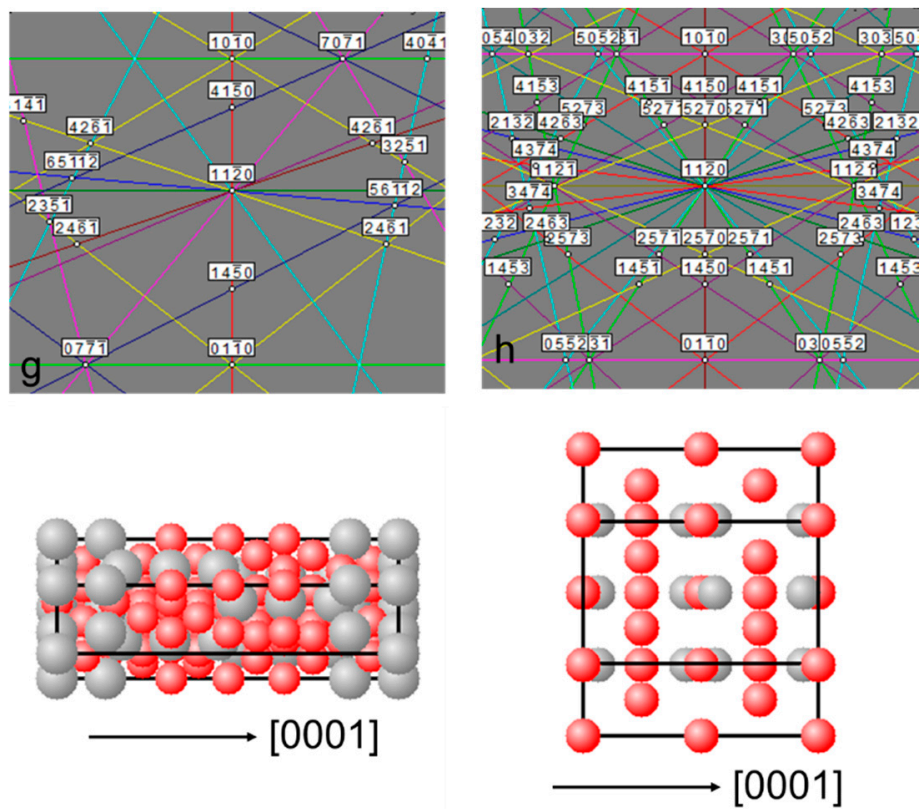

Figure 1. Computer-generated EBSD patterns for the (1120) planes of (a) $\mathrm{LaNi}_{5}$; (b) $\operatorname{Pr}_{5} \mathrm{Co}_{19}$; (c) $\mathrm{Nd}_{5} \mathrm{Co}_{19} ;$ (d) $\mathrm{Ce}_{2} \mathrm{Ni}_{7} ;$ (e) $\mathrm{Pr}_{2} \mathrm{Ni}_{7} ;$ (f) $\mathrm{CeNi}_{3} ;$ (g) $\mathrm{PrNi}_{3}$; and (h) $\mathrm{NbCr}_{2}$ (hexagonal).

SEM-backscattered electron image (BEI) of the 8-h annealed sample is shown in Figure 2, and several spots were studied in detail (spots Z1 to Z6, A to C, and Y1 to Y13). For spots Z1 to Z6, their original EBSD patterns, fitted patterns, and simulations of grain orientation are shown in Figure 3. Other than the base structure ( $\mathrm{LaNi}_{5}$, spot $\mathrm{Z1}$ ), both the $\mathrm{A}_{2} \mathrm{~B}_{7}$ (spots $\mathrm{Z2}$ and $\mathrm{Z3}$ ) and $A B_{3}$ (spot $Z 4$ ) superlattice structures, $M g$ metal (spot Z5), and $A B_{2}$ (spot Z6) phases are found as the new phases. All the patterns are blurry, which can be caused by multiple factors: besides the issues of imperfection in the sample polish and limited camera resolution, strains in the alloy can also influence the band contrasts.

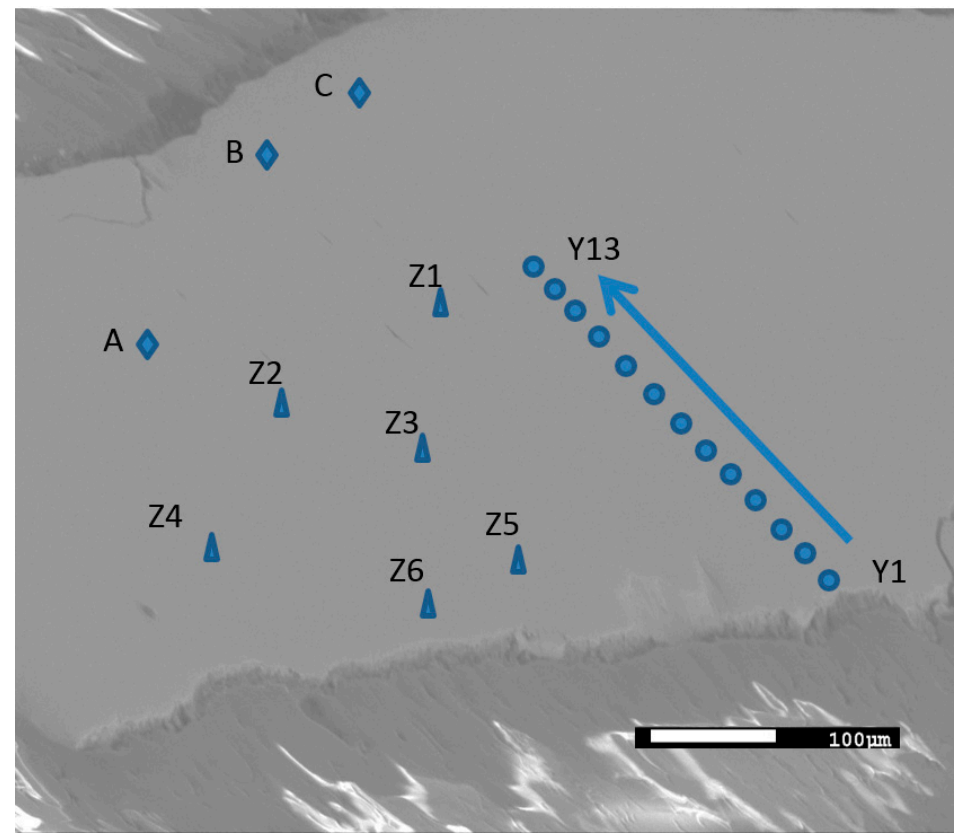

Figure 2. SEM-BEI of the 8-h annealed sample. Structures of spots $\mathrm{Z} 1$ to $\mathrm{Z} 6$ and A to $\mathrm{C}$ were studied by EBSD. Compositions of spots Y1 to Y13 were measured by EDS. 

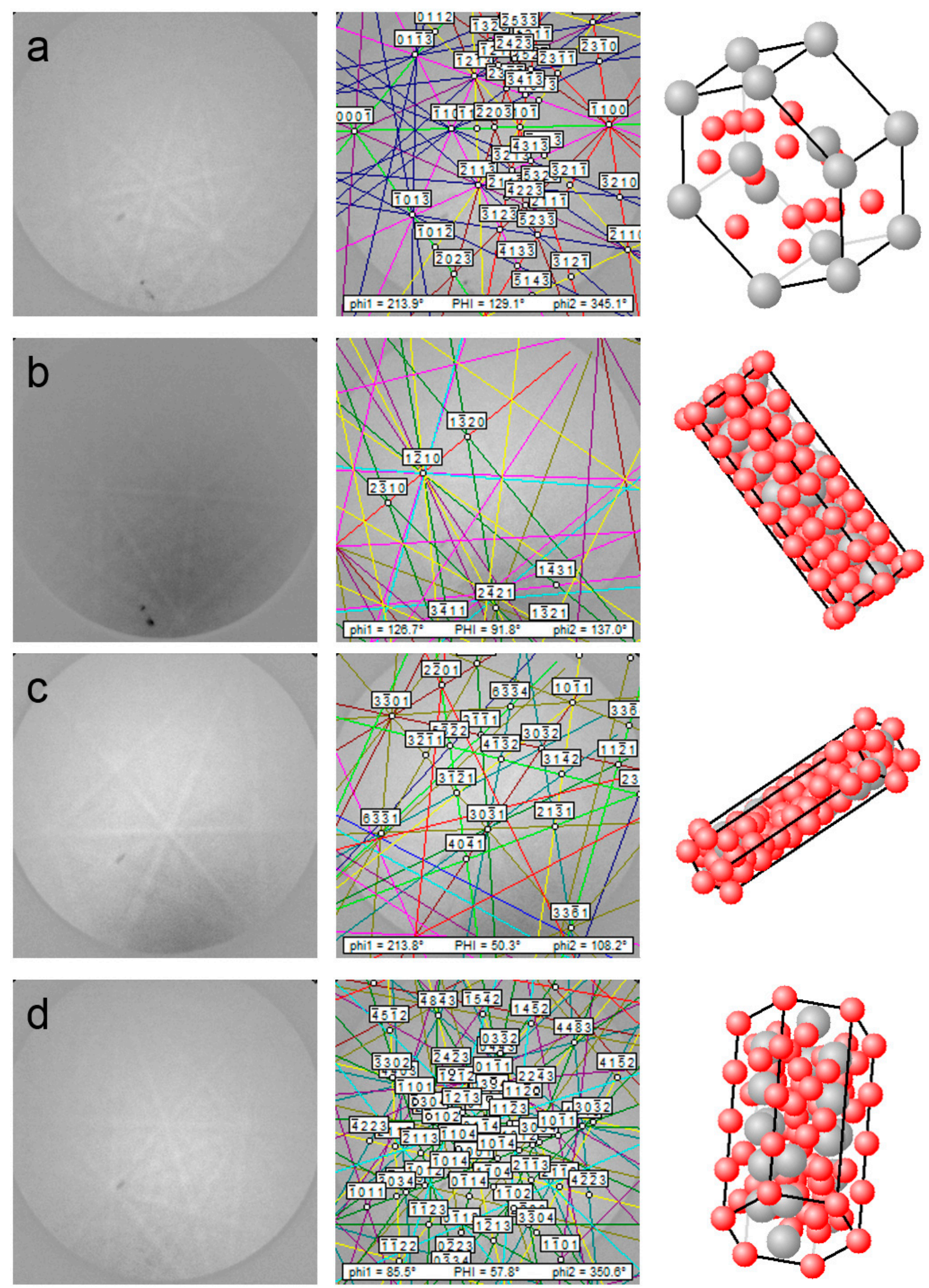

Figure 3. Cont. 

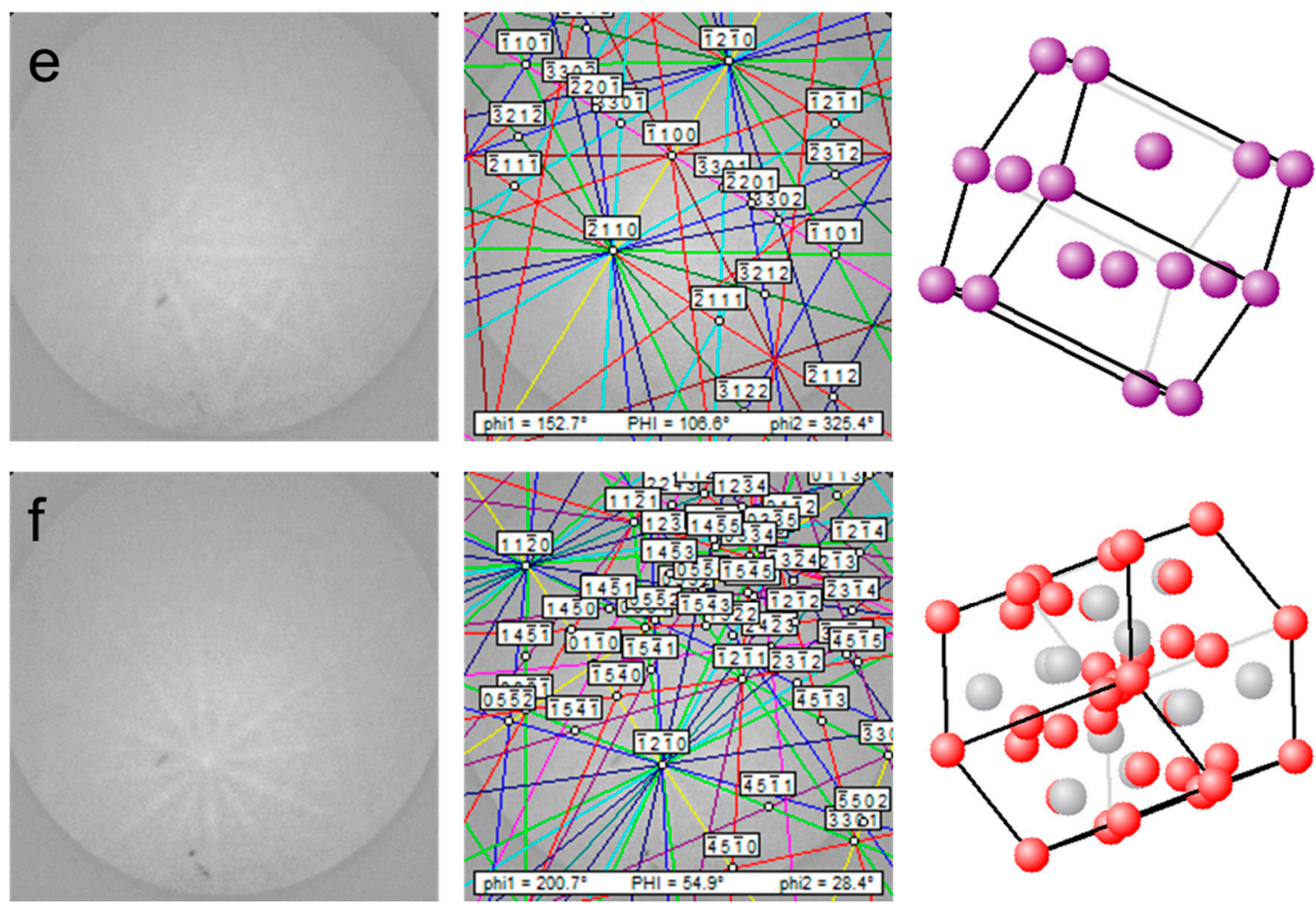

Figure 3. Original EBSD patterns, fitted patterns, and simulations of grain orientation from spots (a) Z1: $\mathrm{LaNi}_{5}$; (b) Z2: $\mathrm{Ce}_{2} \mathrm{Ni}_{7}$; (c) Z3: $\mathrm{Pr}_{2} \mathrm{Ni}_{7}$; (d) Z4: $\mathrm{CeNi}_{3}$; (e) Z5: Mg; and (f) Z6: $\mathrm{NbCr}_{2}$ of the 8-h annealed sample (Figure 2).

Elastic and plastic strains have been reported to cause other changes in the EBSD patterns [26]. Figure 4 shows the EBSD patterns from spots $\mathrm{A}$ to $\mathrm{C}$, and they are identified as $\mathrm{LiNi}_{5}, \mathrm{Ce}_{2} \mathrm{Ni}_{7}$, and $\mathrm{Pr}_{2} \mathrm{Ni}_{7}$, respectively. Except for the blurriness, a new band (B2 in Figure 4b) and bands with a slight rotation (A1 in Figure 4a), a shift (A2 in Figure 4a), a narrower diffraction width (B1 in Figure $4 \mathrm{~b}$ ), and a wider diffraction width (C1 in Figure $4 \mathrm{c}$ ) are observed. Figure 5 shows the schematic diagrams of a few lattice distortions that may cause the changes in the EBSD patterns. Elastic strains distort the crystal lattice. Winkelmann reported that if the elastic strains uniformly dilate the lattice, changes in the EBSD patterns only occur in bandwidth [27]. If other lattice distortions exist, such as partially-lengthened bonds in the lattice (Figure 5b), shifts in some zone axes in the EBSD patterns can occur [26]. Keller et al. [28] reported that a "bent" crystal, as shown in Figure 5c, leads to a slight degradation in pattern quality and a minor band rotation. Since the planes within the diffraction volume are no longer exactly parallel to each other, blurring of diffraction bands and band rotation occur and are caused by the slight changes in Bragg angles. Plastic strains lead to dislocations in the crystal lattice, and Figure 5d,e demonstrate two types of dislocations. The region in the material with a high dislocation density with a net Burgers vector of zero is considered to have statistically stored dislocations (SSD) (Figure 5d). The resulting pattern in the area containing SSDs is degraded because of the local perturbations of diffracting lattice planes that result in incoherent scattering [26]. The area with dislocations with a net-nonzero Burgers vector have geometrically-necessary dislocations (GND). Arrays of GNDs can form subgrain boundaries (Figure 5e) and degrade the EBSD pattern quality by the superposition of patterns from neighboring subgrains with a small rotation in between [26,28]. The influences of misorientation on the quality of EBSD pattern are further elaborated in Supplemental 1 with a SEM micrograph showing three locations with small misorientations (Figure S1) and the corresponding EBSD patterns (Figure S2). 


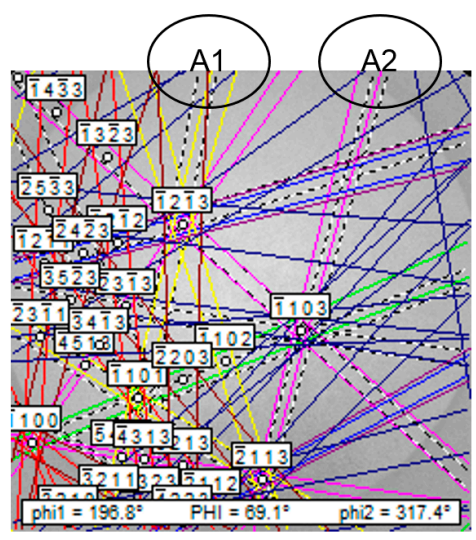

(a)

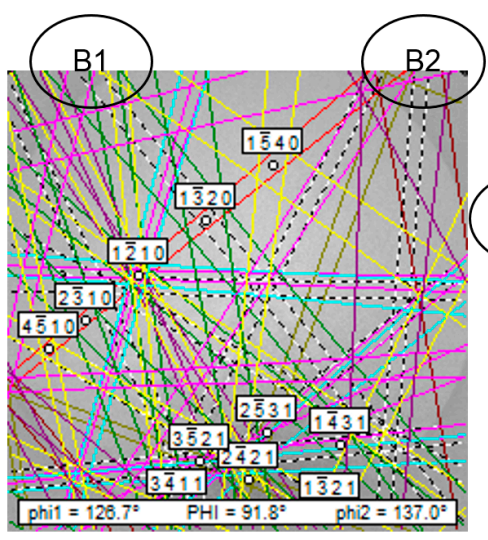

(b)

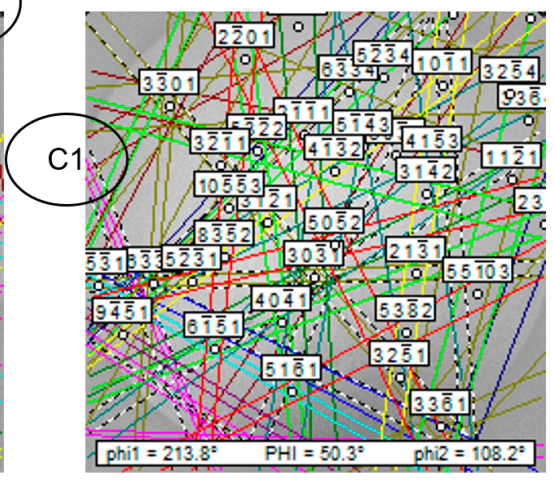

(c)

Figure 4. Comparison of original and computer-generated EBSD patterns from spots (a) A: $\mathrm{LaNi}_{5}$; (b) $\mathrm{B}$ : $\mathrm{Ce}_{2} \mathrm{Ni}_{7}$; and (c) $\mathrm{C}: \mathrm{Pr}_{2} \mathrm{Ni}_{7}$ of the 8-h annealed sample (Figure 2). Solid-color lines indicate the width of computer-generated band. Dashed-black lines show the width of actual band. A new band (B2) and bands with a slight rotation (A1), a shift (A2), a narrower width (B1), and a wider width (C1) are observed.

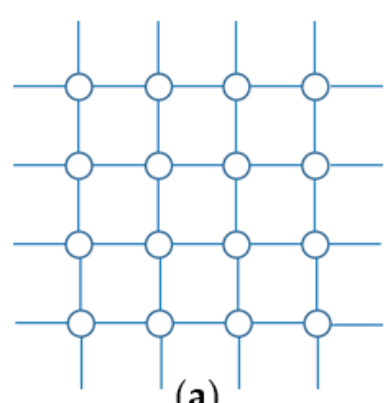

(a)

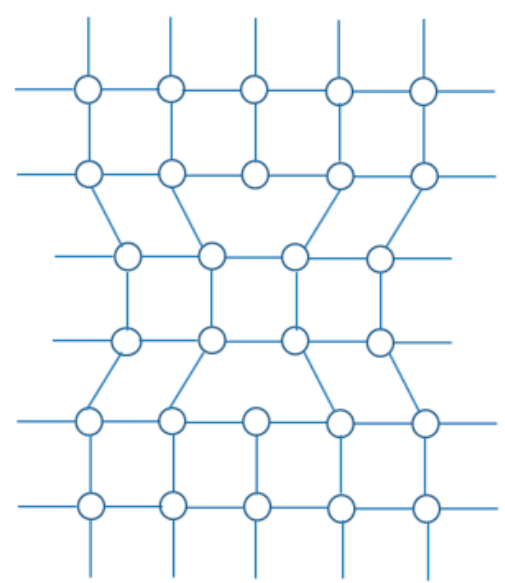

(d)

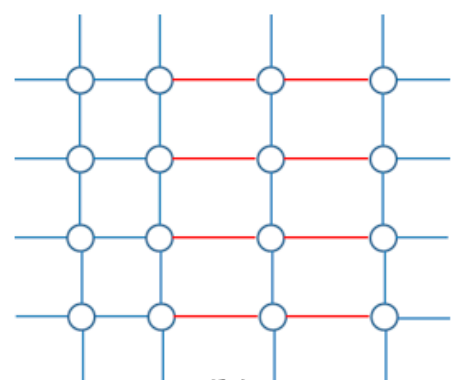

(b)

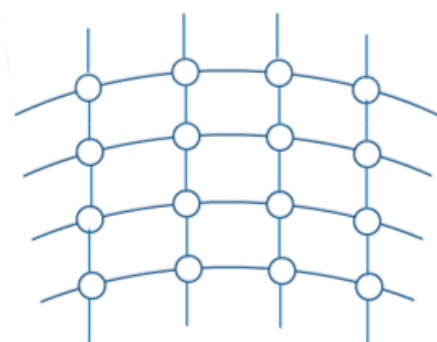

(c)

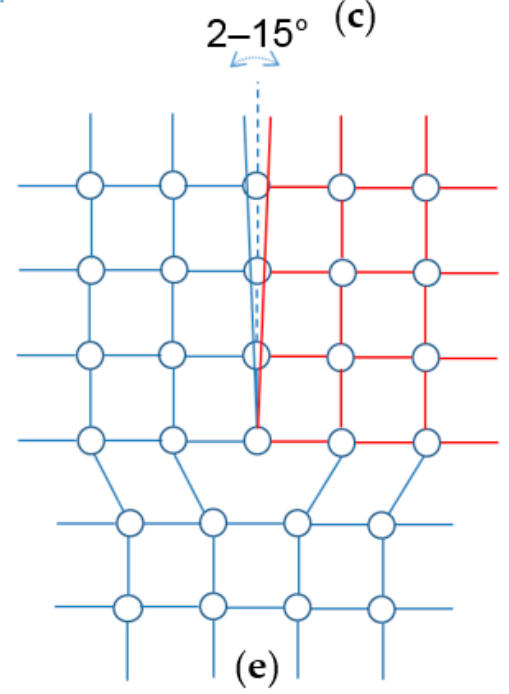

Figure 5. Schematic diagrams of (a) a regular crystal lattice; (b) a strained lattice with uniaxial lengthened bonds; (c) a bent lattice; (d) a distorted lattice with symmetric vacancy defects; and (e) a lattice with a subgrain boundary.

In this study, the La-Mg-Ni alloys were prepared by a solid-state method with Mg diffusing into the $\mathrm{LaNi}_{5}$ alloy. Therefore, both elastic and plastic strains were formed during the Mg-diffusion process and have strong influences on the EBDS pattern clarity. During the Mg-diffusion process, defects in the raw $\mathrm{LaNi}_{5}$ alloys were generated while new phases were formed. Physical and 
chemical properties of the La-Mg-Ni alloys prepared by this method are affected by the distribution of defects, and compositions and abundances of constituent phases. Therefore, investigating the alloys' microstructures by the EBSD technique becomes important.

\subsection{Phase Distribution}

\subsubsection{Element Distribution}

To fully characterize the alloys' microstructures, EDS elemental mappings were conducted on all four alloys (4 h-, $8 \mathrm{~h}-, 16 \mathrm{~h}$-, and 32-h annealed samples), and the results are shown in Figure 6 . While La and Ni distribute uniformly in all alloys, $\mathrm{Mg}$ shows a high concentration at the edges of all alloys. The EDS results of spots Y1 to Y13 in the SEM micrograph of the 8-h annealed sample (Figure 2) are listed in Table 1, which demonstrate the uneven distribution of $\mathrm{Mg}$ from the edge to center of alloy. Penetration of $\mathrm{Mg}$ into the 8-h annealed sample is about 100 microns. The value of $\mathrm{Ni} /(\mathrm{La}+\mathrm{Mg})$ varies from 1.49 to 5.32 , and the varying trend indicates that the phase changes along the longitudinal section (from one surface to another) of alloy. However, it must be stated that EDS is a semi-quantitative analysis method, so other technologies have to be combined with EDS to validate the phase distribution.

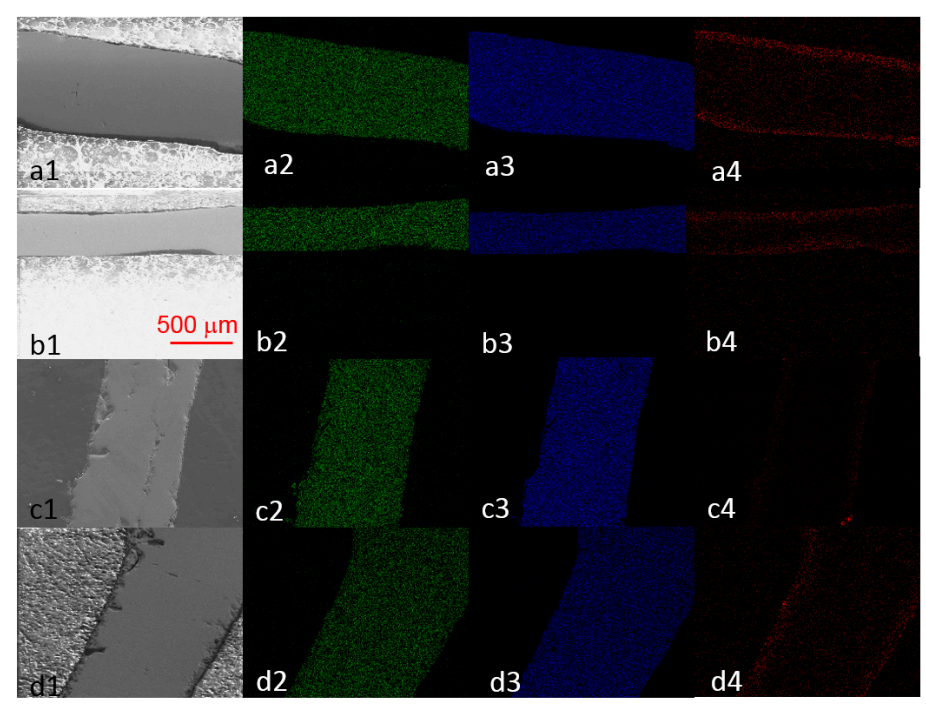

Figure 6. (a1,b1,c1,d1) SEM-BEIs and elemental mappings of $(\mathbf{a} 2, \mathbf{b} 2, \mathbf{c} 2, \mathbf{d} 2) \mathrm{La},(\mathbf{a} 3, \mathbf{b} 3, \mathbf{c} 3, \mathrm{~d} 3) \mathrm{Ni}$, and $(\mathbf{a} 4, \mathbf{b 4}, \mathbf{c 4}, \mathbf{d} 4) \mathrm{Mg}$ of the $4 \mathrm{~h}-, 8 \mathrm{~h}-, 16 \mathrm{~h}-$, and 32-h annealed samples, respectively.

Table 1. Chemical compositions (in at \%) from spots $\mathrm{Y} 1$ to $\mathrm{Y} 13$ of the 8 -h annealed sample (Figure 2).

\begin{tabular}{ccccc}
\hline Spot & $\mathbf{M g}$ & $\mathbf{L a}$ & $\mathbf{N i}$ & $\mathbf{N i} /(\mathbf{L a}+\mathbf{M g})$ \\
\hline Y1 & 24.01 & 16.19 & 59.79 & 1.49 \\
Y2 & 16.42 & 12.94 & 70.64 & 2.41 \\
Y3 & 13.12 & 14.09 & 72.78 & 2.67 \\
Y4 & 1.29 & 16.11 & 82.6 & 4.75 \\
Y5 & 0.00 & 16.45 & 83.55 & 5.08 \\
Y6 & 0.28 & 16.27 & 83.45 & 5.04 \\
Y7 & 0.29 & 16.10 & 83.61 & 5.10 \\
Y8 & 0.00 & 16.71 & 83.29 & 4.98 \\
Y9 & 0.00 & 15.82 & 84.18 & 5.32 \\
Y10 & 0.00 & 16.72 & 83.28 & 4.98 \\
Y11 & 0.00 & 16.24 & 83.76 & 5.16 \\
Y12 & 1.00 & 16.26 & 82.74 & 4.79 \\
Y13 & 8.32 & 15.16 & 76.54 & 3.26 \\
\hline
\end{tabular}




\subsubsection{Phase Distribution}

As an example, phase identification mapping by EBSD of the 16-h annealed sample is shown in Figure 7. Six phases, including $\mathrm{LaNi}_{5}, \mathrm{Ce}_{2} \mathrm{Ni}_{7}, \mathrm{Pr}_{2} \mathrm{Ni}_{7}, \mathrm{CeNi}_{3}, \mathrm{NbCr}_{2}$ (hexagonal), and $\mathrm{Mg}$, can be identified. In the investigated area of the 16-h annealed sample, the $\operatorname{Pr}_{5} \mathrm{Co}_{19}, \mathrm{Nd}_{5} \mathrm{Co}_{19}$, and $\mathrm{PuNi}_{3}$ structures are not found. A gradient of phase abundance can be observed for most phases. $\mathrm{LaNi}_{5}$, the unreacted material, is concentrated in the center. While the diffuse-in $\mathrm{Mg}$ is concentrated at the edge, $\mathrm{Ce}_{2} \mathrm{Ni}_{7}$, one of the important target products [9], is also concentrated at the edge. Existence of pure $\mathrm{Mg}$ phase is validated in Supplement 2 with SEM micrographs (Figure S3) and EDS results showing high-Mg contents (Table $\mathrm{S} 1$ ). $\mathrm{Pr}_{2} \mathrm{Ni}_{7}$, another one of the target products, is located mainly between the $\mathrm{LaNi}_{5}$ and $\mathrm{Mg}$ phases. Abundances of the six phases in the investigated area are summarized in the table included in Figure 7. The $\mathrm{LaNi}_{5}$ abundance is $27.2 \%$, and the combined abundance of $\mathrm{Ce}_{2} \mathrm{Ni}_{7}$ and $\mathrm{Pr}_{2} \mathrm{Ni}_{7}$ is $15.8 \%$. The $\mathrm{CeNi}_{3}$ and $\mathrm{NbCr}_{2}$ phases are products from the overreaction of $\mathrm{Ce}_{2} \mathrm{Ni}_{7}$ and $\mathrm{Pr}_{2} \mathrm{Ni}_{7}$ with $\mathrm{Mg}$. Future work will focus on increasing the $\mathrm{Ce}_{2} \mathrm{Ni}_{7}$ and $\mathrm{Pr}_{2} \mathrm{Ni}_{7}$ phase abundances.

Edge
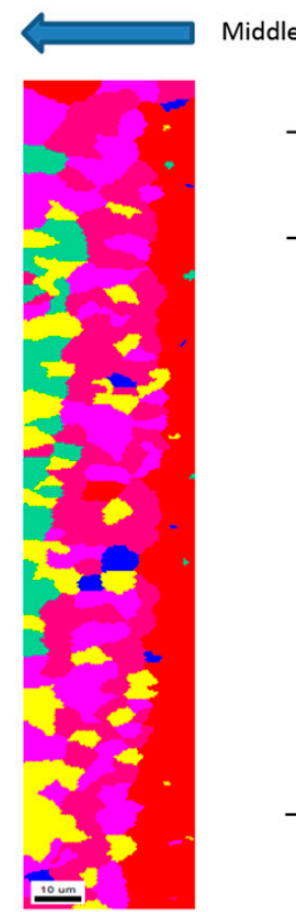

\begin{tabular}{cccc}
\hline Color block & Phase & JCPDS & Fraction \% \\
\hline$\square$ & $\mathrm{LaNi}_{5}$ & $00-055-0277$ & 27.2 \\
\hline & $\mathrm{Pr}_{5} \mathrm{Co}_{19}$ & $04-004-1477$ & 0 \\
\hline & $\mathrm{Nd}_{5} \mathrm{Co}_{19}$ & $04-004-1478$ & 0 \\
\hline & $\mathrm{Ce}_{2} \mathrm{Ni}_{7}$ & $04-007-1092$ & 14.3 \\
\hline & $\mathrm{Pr}_{2} \mathrm{Ni}_{7}$ & $01-081-8491$ & 1.50 \\
\hline & $\mathrm{CeNi}_{3}$ & $04-007-1090$ & 21.1 \\
\hline & $\mathrm{Pu} \mathrm{Ni}_{3}$ & $04-007-1091$ & 0 \\
\hline & $\mathrm{NbCr}_{2}$ & $04-001-2137$ & 28.5 \\
\hline & $\mathrm{Mg}$ & $04-01502580$ & 7.40 \\
\hline
\end{tabular}

Figure 7. EBSD phase identification mapping and quantification of the $16-\mathrm{h}$ annealed sample. The grain tolerance angle is $15^{\circ}$, and the minimum grain size is $3 \mu \mathrm{m}$.

\subsection{3. $\mathrm{LaNi}_{5}$ and $\mathrm{Mg}$ Grain Distributions and Orientations}

Inverse pole figure (IPF) and EBSD mapping, EBSD diffraction patterns, and crystal simulations of $\mathrm{LaNi}_{5}$ of the 16-h annealed sample are shown in Figure 8. In Figure 8a,b, color channels in red, green, and blue represent, [0001], [1010], and [2110] of LaNi . Figure 8a shows only two grain orientations for $\mathrm{LaNi}_{5}$. Grain orientations are described in the form of the Euler angle in Figure 8c,e. Figure 8a shows that grains with orientation 2 are isolated and much smaller in abundance than those with orientation 1. The right side of Figure 8a (the center of alloy) is a single $\mathrm{LaNi}_{5}$ grain without reacting with $\mathrm{Mg}$. The interaction with $\mathrm{Mg}$ stopped at the grain boundary between the $\mathrm{LaNi}_{5}$ phase with orientation 1 and the $\mathrm{LaNi}_{5}$ phase with orientation 2. This is the proof that the inter-diffusion of $\mathrm{Mg}$ into the host $\mathrm{LaNi}_{5}$ alloy is through a specific direction (presumable along the $a b$-plane) and stops 
at the grain boundary. Therefore, increasing the grain size of the host $\mathrm{LaNi}_{5}$ alloy can enhance the diffusion of $\mathrm{Mg}$ into the bulk.

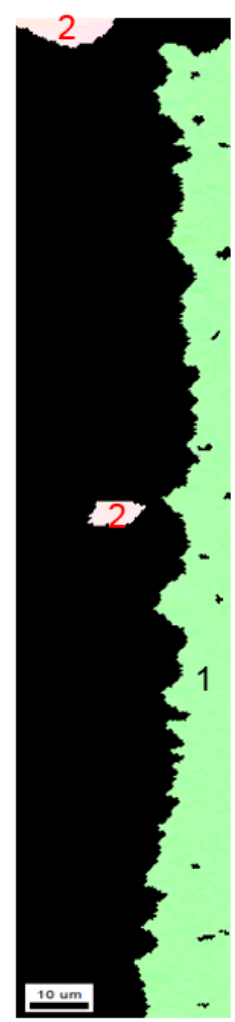

(a)

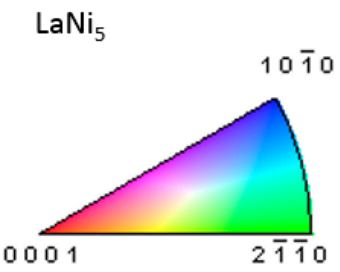

(b)

Figure 8. (a) IPF and EBSD mapping; (b) color assignment; (c) EBSD pattern for grain orientation 1 and (d) its corresponding crystal simulation; and (e) EBSD pattern for grain orientation 2 and (f) its corresponding crystal simulation of the $\mathrm{LaNi}_{5}$ phase of the 16-h annealed sample.

IPF and EBSD mapping, EBSD diffraction patterns, and crystal simulations of $\mathrm{Mg}$ of the 16-h annealed sample are shown in Figure 9. Three different crystallographic orientations are found for $\mathrm{Mg}$. Grains with orientation 1 distribute at the edge of alloy and are the largest in size. Grains with orientation 3 distribute close to the center of alloy and are the smallest. After diffusing into the host, $\mathrm{Mg}$ first agglomerates into individual grains with the same crystallographic orientation (related to the host orientation) before reacting with the host to form the superlattice phases. It is interesting to find that the superlattice phases are formed by the reaction of $\mathrm{LaNi}_{5}$ with the $\mathrm{Mg}$ crystal but not the Mg vapor. 


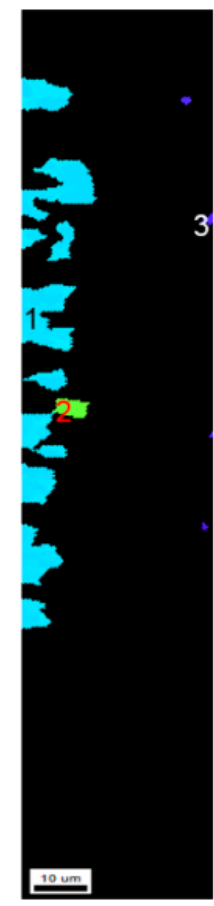

(a)

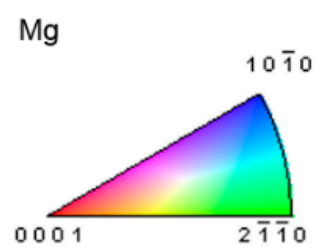

(b)

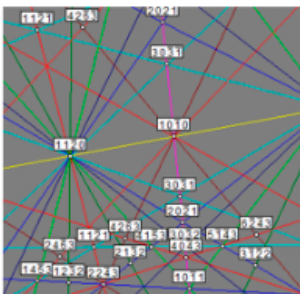

(c)

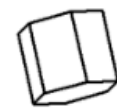

(d)

Grain orientation 3 Euler angles: $(255.7,81.9,241.0)$

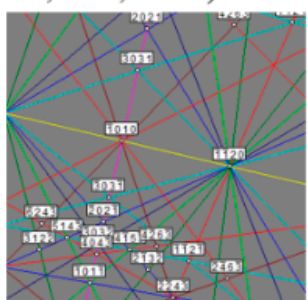

$(\mathrm{g})$

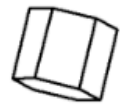

(h)

Figure 9. (a) IPF and EBSD mapping; (b) color assignment; (c) EBSD pattern for grain orientation 1 and (d) its corresponding crystal simulation; (e) EBSD pattern for grain orientation 2 and (f) its corresponding crystal simulation; and (g) EBSD pattern for grain orientation 3 and (h) its corresponding crystal simulation of the $\mathrm{Mg}$ phase of the 16-h annealed sample.

\subsection{4. $\mathrm{Ce}_{2} \mathrm{Ni}_{7}$ and $\mathrm{Pr}_{2} \mathrm{Ni}_{7}$ Grain Distributions and Orientations}

IPF and EBSD mapping, image quality (IQ) diffraction pattern and grain boundary map, and grain size distribution of $\mathrm{Ce}_{2} \mathrm{Ni}_{7}$ of the 16-h annealed sample are shown in Figure 10. Unlike $\mathrm{LaNi}_{5}$ and $\mathrm{Mg}$, the $\mathrm{Ce}_{2} \mathrm{Ni}_{7}$ phase shows more grain orientations (Figure $10 \mathrm{a}$ ). IQ patterns can be used to characterize the defect distribution in grains and is especially useful for the strain mapping [20]. Figure 10c shows that some grains are darker than the others, which indicates that concentrated defects and residual strains exist in these darker grains. A grain boundary is formed by the accumulation of edge dislocations. In this study, two types of boundaries are characterized: low-angle grain boundary (LAGB) and high-angle grain boundary (HAGB). LAGB subdivides a grain into two equiaxial cells and forms subgrains, which may increase the plastic deformation. In this study, we define the lattice misorientation of LAGB-separated grain zones to be from $2^{\circ}$ to $15^{\circ}$. A grain boundary with a misorientation $\geq 15^{\circ}$ is denoted as HAGB, which differentiates a grain from its initial microstructure and creates a new grain. Figure 10c indicates the grain boundary distribution of the $\mathrm{Ce}_{2} \mathrm{Ni}_{7}$ phase in the $16-\mathrm{h}$ annealed sample. Amount of LAGBs in the $\mathrm{Ce}_{2} \mathrm{Ni}_{7}$ phase is $40.3 \%$, which is much higher than that in the $\mathrm{LaNi}_{5}$ or $\mathrm{Mg}$ phase and suggests a high density of defects in the $\mathrm{Ce}_{2} \mathrm{Ni}_{7}$ grains. Grain size distribution is shown in Figure $10 \mathrm{~d}$. Average grain diameter of the $\mathrm{Ce}_{2} \mathrm{Ni}_{7}$ phase is $7 \mu \mathrm{m}$. IPF and EBSD mapping, EBSD diffraction patterns, and crystal simulations of $\mathrm{Pr}_{2} \mathrm{Ni}_{7}$ in the 16-h annealed sample are shown in Figure 11. Unlike $\mathrm{Ce}_{2} \mathrm{Ni}_{7}$, the $\mathrm{Pr}_{2} \mathrm{Ni}_{7}$ phase has only two different orientations and a smaller grain size of about $4 \mu \mathrm{m}$. 


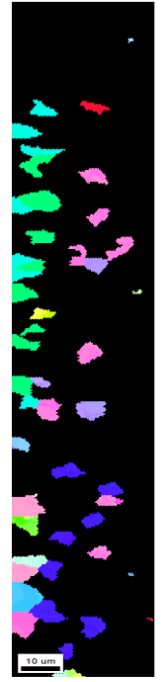

(a)

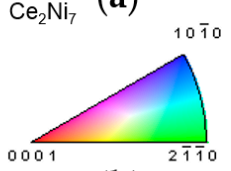

(b)

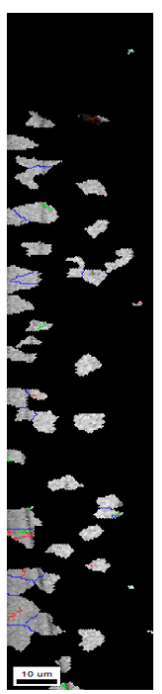

Boundaries: Rotation Angle $\frac{\text { Min }}{2^{\circ}} \frac{\text { Max }}{5^{\circ}} \frac{\text { Fraction }}{0.217}$ $\begin{array}{lll}5^{\circ} & 15^{\circ} & 0.186\end{array}$ $\begin{array}{ccc}5^{\circ} & 15^{\circ} & 0.186 \\ 15^{\circ} & 180^{\circ} & 0.598\end{array}$

(c)

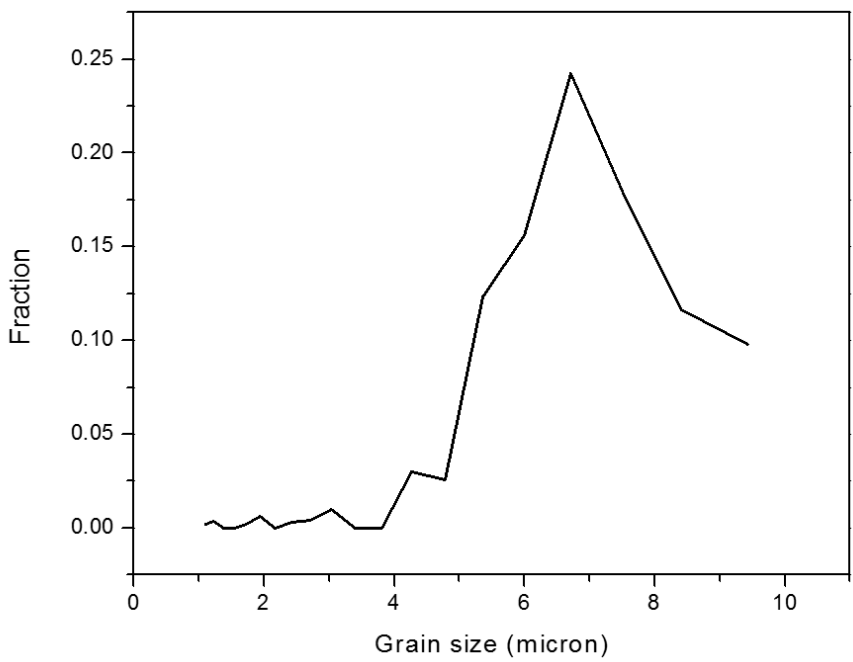

(d)

Figure 10. (a) IPF and EBSD mapping; (b) color assignment; (c) IQ diffraction pattern and grain boundary map; and (d) grain size distribution of the $\mathrm{Ce}_{2} \mathrm{Ni}_{7}$ phase of the $16-\mathrm{h}$ annealed sample.

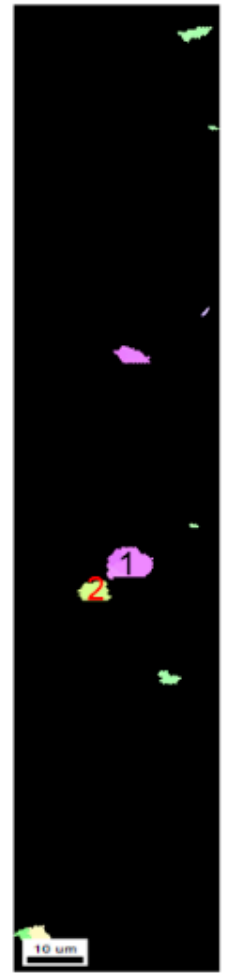

(a)

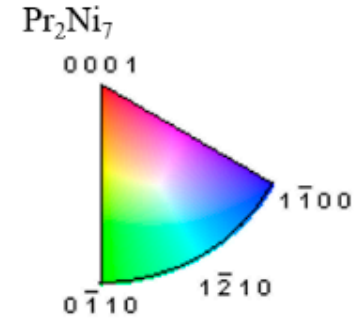

(b)

Grain orientation 1 Euler angles: $(185.8,116.2,20.0)$

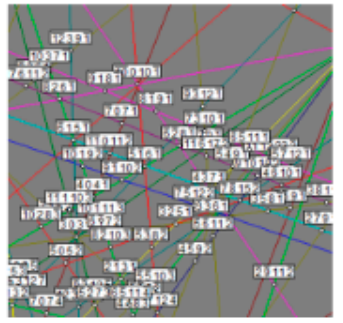

(c)

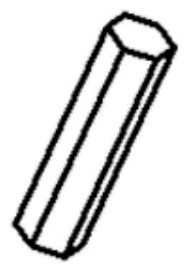

(d)

Grains orientation 2 Euler angles: $(66.2,58.0,11.8)$

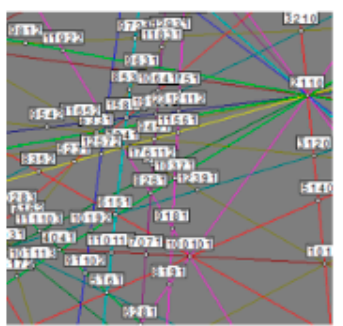

(e)

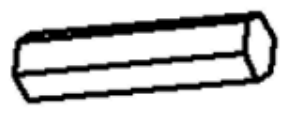

(f)

Figure 11. (a) IPF and EBSD mapping; (b) color assignment; (c) EBSD pattern for grain orientation 1 and (d) its corresponding crystal simulation; and (e) EBSD pattern for grain orientation 2 and (f) its corresponding crystal simulation of the $\mathrm{Pr}_{2} \mathrm{Ni}_{7}$ phase of the $16-\mathrm{h}$ annealed sample. 


\subsection{Alignment in Crystallographic Orientations}

Figure 12a shows the EBSD phase identification mapping of the 8-h annealed sample. [0001]s of $\mathrm{LaNi} 5$ and Pr2Ni7 in the green circle are found to be parallel to each other, and [0001]s of LaNi5 and $\mathrm{Ce}_{2} \mathrm{Ni}_{7}$ in the black circle are also parallel (Figure 12b-e). This information gives a hint about the grain growth mechanism of the $\mathrm{A}_{2} \mathrm{~B}_{7}$-type phases during the diffusion of $\mathrm{Mg}$ into the $\mathrm{AB}_{5}$ alloy. Structures of the La-Mg-Ni superlattice phases are composed of the $\mathrm{A}_{2} \mathrm{~B}_{4}$ and the $\mathrm{AB}_{5}$ slabs [23]. The alignments of $\mathrm{LaNi}_{5}$ and $\mathrm{Pr}_{2} \mathrm{Ni}_{7}$ in the $c$-axis and $\mathrm{LaNi}_{5}$ and $\mathrm{Ce}_{2} \mathrm{Ni}_{7}$ in the $c$-axis imply that $\mathrm{Mg}$ diffuses into $\mathrm{LaNi}_{5}$ and forms the $\mathrm{A}_{2} \mathrm{~B}_{4}$ slab through the $a b$-plane and, therefore, the $c$-axis orientation remains unchanged after the superlattice phase formation.

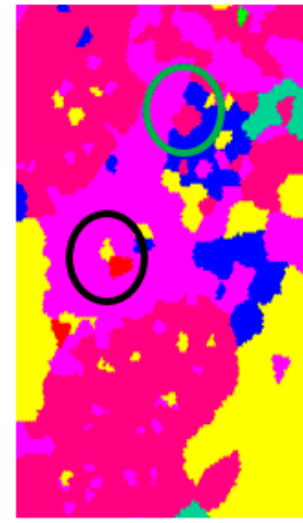

(a)

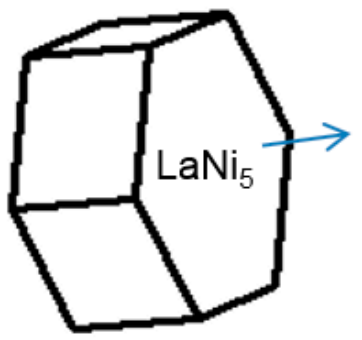

(b)

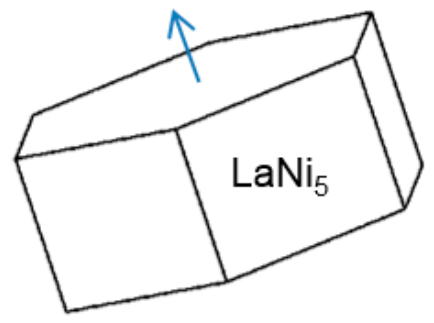

(d)

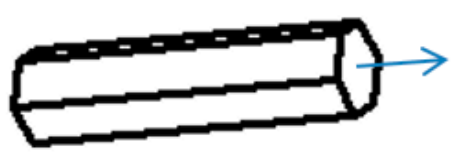

$\mathrm{Pr}_{2} \mathrm{Ni}_{7}$

(c)

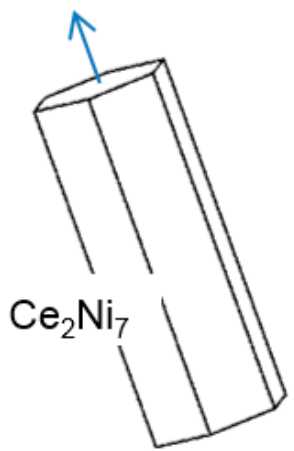

(e)

Figure 12. Crystallographic orientation alignments in [0001] demonstrated by (a) an IPF-EBSD map; orientations of (b) $\mathrm{LaNi}_{5}$ and (c) neighboring $\mathrm{Pr}_{2} \mathrm{Ni}_{7}$ in the green circle; and orientations of (d) $\mathrm{LaNi}_{5}$ and (e) neighboring $\mathrm{Ce}_{2} \mathrm{Ni}_{7}$ in the black circle of the 8-h annealed sample.

\subsection{Effect of Process Temperature on Phase Development}

EBSD mapping was performed in an area of $30 \times 100$ square microns close to the edge of each sample. The results may not be very accurate because of the limited sampling areas and large variations in distribution of the superlattice phases. Nevertheless, the calculated phase abundances are compared in Table 2. The conversion from $\mathrm{LaNi}_{5}$ to other phases is more complete with the increase in process time and reaches $98.2 \mathrm{wt} \%$ at a processing time of $32 \mathrm{~h}$. Abundance of the most desirable $\mathrm{Ce}_{2} \mathrm{Ni}_{7}$ phase is about $25 \mathrm{wt} \%$ and not very sensitive to the processing time. Abundance of the $\mathrm{A}_{2} \mathrm{~B}_{7}$ phases (both $\mathrm{Ce}_{2} \mathrm{Ni}_{7}$ and $\mathrm{Pr}_{2} \mathrm{Ni}_{7}$ ) increases from 42.5 to $45.8 \mathrm{wt} \%$ and reduces to $39.2 \mathrm{wt} \%$ as 
the processing time increases from 4 to $32 \mathrm{~h}$. The unwanted $\mathrm{AB}_{2}$ and $\mathrm{AB}_{3}$ phases (with excessive $\mathrm{Mg}$-content) cannot be eliminated with the increase in processing time. Future development work will focus on the reduction of the Mg-supply and/or addition of a second annealing treatment without $\mathrm{Mg}$.

Table 2. Phase abundances (in wt \%) obtained by EBSD mapping of the 4-h, 8-h, 16-h, and 32-h annealed samples with a grain tolerance angle of $5^{\circ}$ and a minimum grain size of $2 \mu \mathrm{m}$.

\begin{tabular}{lcccc}
\hline Phase & $\mathbf{4} \mathbf{h}$ & $\mathbf{8} \mathbf{h}$ & $\mathbf{1 6} \mathbf{h}$ & $\mathbf{3 2} \mathbf{h}$ \\
\hline $\mathrm{LaNi}_{5}$ & 13.2 & 5.5 & 4.2 & 1.8 \\
$\mathrm{Ce}_{2} \mathrm{Ni}_{7}$ & 23.5 & 27.3 & 27.6 & 25.5 \\
$\mathrm{Pr}_{2} \mathrm{Ni}_{7}$ & 19.0 & 18.5 & 16.3 & 13.7 \\
$\mathrm{CeNi}_{3}$ & 22.6 & 19.5 & 26.4 & 21.0 \\
$\mathrm{PuNi}_{3}$ & 0.5 & 0.2 & 0.5 & 0.5 \\
$\mathrm{NbCr}_{2}$ & 16.2 & 25.5 & 22.3 & 30.3 \\
$\mathrm{Mg}$ & 4.9 & 3.4 & 2.8 & 7.2 \\
\hline
\end{tabular}

Grain size distributions of all four samples are also compared and listed in Table 3. The 4-h annealed sample has a heavy proportion of medium-size grains (5-12 $\mu \mathrm{m})$ while the 8 -h annealed sample has a much higher percentage of small grains $(1-5 \mu \mathrm{m})$. Longer processing time (16- and 32-h) recovers the percentage of medium-size grains. The reason for the grain size evolution is not clear and requires further studies. The last comparison is on the distribution of misorientation angle in the grain boundary, which is shown in Table 4 . Amount of HAGBs (15 to $\left.180^{\circ}\right)$ decreases with the increase in process time, which suggests the occurrence of lattice cracking.

Table 3. Grain size distributions of the 4-h, 8-h, 16-h, and 32-h annealed samples.

\begin{tabular}{ccccc}
\hline Grain Size $(\boldsymbol{\mu m})$ & $\mathbf{4} \mathbf{h}$ & $\mathbf{8} \mathbf{h}$ & $\mathbf{1 6} \mathbf{h}$ & $\mathbf{3 2} \mathbf{h}$ \\
\hline 1 to 5 & $24 \%$ & $79 \%$ & $35 \%$ & $37 \%$ \\
5 to 12 & $61 \%$ & $16 \%$ & $48 \%$ & $49 \%$ \\
$>12$ & $15 \%$ & $5 \%$ & $16 \%$ & $14 \%$ \\
\hline
\end{tabular}

Table 4. Grain boundary distributions of the 4-h, 8-h, 16-h, and 32-h annealed samples.

\begin{tabular}{cclll}
\hline Grain Boundary $\left(^{\circ}\right)$ & $\mathbf{4} \mathbf{h}$ & $\mathbf{8} \mathbf{h}$ & $\mathbf{1 6} \mathbf{h}$ & $\mathbf{3 2} \mathbf{h}$ \\
\hline 2 to 5 & $11.3 \%$ & $14.4 \%$ & $22.3 \%$ & $22.1 \%$ \\
5 to 15 & $4.3 \%$ & $2.5 \%$ & $0.7 \%$ & $11.4 \%$ \\
15 to 180 & $84.4 \%$ & $83.1 \%$ & $77.0 \%$ & $55.5 \%$ \\
\hline
\end{tabular}

\section{Conclusions}

A gaseous-state Mg-diffusion into an $\mathrm{AB}_{5}$ metal hydride alloy is demonstrated as an effective method to convert a $\mathrm{LaNi}_{5}$ alloy to a multi-phase superlattice alloy. Four La-Mg-Ni superlattice phases are identified by EBSD in the products: $\mathrm{Ce}_{2} \mathrm{Ni}_{7}, \mathrm{Pr}_{2} \mathrm{Ni}_{7}, \mathrm{CeNi}_{3}$, and $\mathrm{PuNi}_{3}$. Additionally, $\mathrm{Mg}$ and $\mathrm{AB}_{2}$ (with the hexagonal $\mathrm{NbCr}_{2}$ structure) phases are also found. Longer process time increases the $\mathrm{LaNi}_{5}$ conversion rate but shows no significant effect on increasing the abundance of the most desirable $\mathrm{Ce}_{2} \mathrm{Ni}_{7}$ phase. Defects are found abundantly in the $\mathrm{Ce}_{2} \mathrm{Ni}_{7}$ and $\mathrm{Pr}_{2} \mathrm{Ni}_{7}$ phases by EBSD, and distributions of the superlattice phases are not uniform. Future activities in reducing the Mg-loading, addition of a second annealing treatment, and increasing the initial grain size of the host alloy are suggested based on the findings in this study. 
Supplementary Materials: The following are available online at http:/ /www.mdpi.com/2313-0105/3/4/40/s1.

Acknowledgments: The authors would like to thank the following individuals for their help: Alan Chan, Jean Nei, and Diana Wong from BASF-Ovonic.

Author Contributions: Xin Zhao prepared the sample and Shuli Yan performed the EBSD study. Kwo-Hsiung and Simon $\mathrm{Ng}$ provided guidance and helped in manuscript preparation.

Conflicts of Interest: The authors declare no conflict of interest.

\section{Abbreviations}

$\begin{array}{ll}\text { RE } & \text { Rare earth } \\ \text { MH } & \text { Metal hydride } \\ \text { Ni/MH } & \text { Nickel/metal hydride } \\ \text { HRD } & \text { High-rate dischargeability } \\ \text { EBSD } & \text { Electron backscatter diffraction } \\ \text { SEM } & \text { Scanning electron microscope } \\ \text { EDS } & \text { Energy dispersive spectroscopy } \\ \text { BEI } & \text { Backscattered electron image } \\ \text { SSD } & \text { Statistically stored dislocations } \\ \text { GND } & \text { Geometrically necessary dislocations } \\ \text { IPF } & \text { Inverse pole figure } \\ \text { IQ } & \text { Image quality } \\ \text { LAGB } & \text { Low-angle grain boundary } \\ \text { HAGB } & \text { High-angle grain boundary }\end{array}$

\section{References}

1. Yasuoka, S.; Magari, Y.; Murata, T.; Tanaka, T.; Ishida, J.; Nakamura, H.; Nohma, T.; Kihara, M.; Baba, Y.; Teraoka, H. Development of high-capacity nickel-metal hydride batteries using superlattice hydrogen-absorbing alloys. J. Power Sources 2006, 156, 662-666. [CrossRef]

2. Teraoka, H. Development of Low Self-Discharge Nickel-Metal Hydride Battery. Available online: http:/ / www.scribd.com/doc/9704685/Teraoka-Article-En (accessed on 9 April 2016).

3. Kai, T.; Ishida, J.; Yasuoka, S.; Takeno, K. The effect of nickel-metal hydride battery's characteristics with structure of the alloy. In Proceedings of the 54th Battery Symposium in Japan, Osaka, Japan, 7-9 October 2013; p. 210.

4. Takasaki, T.; Nishimura, K.; Saito, M.; Fukunaga, H.; Iwaki, T.; Sakai, T. Cobalt-free nickel-metal hydride battery for industrial applications. J. Alloys Compd. 2013, 580, S378-S381. [CrossRef]

5. Teraoka, H. Development of Ni-MH EThSS with Lifetime and Performance Estimation Technology. In Proceedings of the 34th International Battery Seminar \& Exhibit, Fort Lauderdale, FL, USA, 20-23 March 2017.

6. Teraoka, H. Ni-MH Stationary Energy Storage: Extreme Temperature \& Long Life Developments. In Proceedings of the 33th International Battery Seminar \& Exhibit, Fort Lauderdale, FL, USA, 21-24 March 2016.

7. Teraoka, H. Development of Highly Durable and Long Life Ni-MH Batteries for Energy Storage Systems. In Proceedings of the 32th International Battery Seminar \& Exhibit, Fort Lauderdale, FL, USA, 9-12 March 2015.

8. Ouchi, T.; Young, K.; Moghe, D. Reviews on the Japanese Patent Applications regarding nickel/metal hydride batteries. Batteries 2016, 2, 21. [CrossRef]

9. Young, K.; Ouchi, T.; Nei, J.; Koch, J.M.; Lien, Y. Comparison among constituent phases in superlattice metal hydride alloys for batter applications. Batteries 2017, 3, 34. [CrossRef]

10. Young, K.; Yasuoka, S. Past, present, and future of metal hydride alloys in nickel-metal hydride batteries. In Proceedings of the 14th International Symposium on Metal-Hydrogen Systems, Manchester, UK, 21-25 July 2014. 
11. Hayakawa, H.; Enoki, H.; Akiba, E. Annealing conditions with Mg vapor-pressure control and hydrogen storage characteristic of $\mathrm{La}_{4} \mathrm{MgNi}_{19}$ hydrogen storage alloy. Jpn. Inst. Met. 2006, 70, 158-161. (In Japanese) [CrossRef]

12. Crivello, J.-C.; Zhang, J.; Latroche, M. Structural stability of $\mathrm{AB}_{y}$ phases in the (La,Mg)-Ni system obtained by density functional theory calculations. J. Phys. Chem. 2011, 115, 25470-25478.

13. Crivello, J.-C.; Gupta, M.; Latroche, M. First principles calculations of (La, $\mathrm{Mg})_{2} \mathrm{Ni}_{7}$ hydrides. J. Alloys Compd. 2015, 645, S5-S8. [CrossRef]

14. Young, K.; Ouchi, T.; Huang, B. Effects of annealing and stoichiometry to $(\mathrm{Nd}, \mathrm{Mg})(\mathrm{Ni}, \mathrm{Al})_{3.5} \mathrm{metal}$ hydride alloys. J. Power Sources 2012, 215, 152-159. [CrossRef]

15. Zhao, X.; Li, B.; Zhu, X.; Han, S.; Yan, H.; Ji, L.; Wang, L.; Li, J.; Xiong, W.; Jia, T. Preparation Method of Low-Melting Point Metal Alloy. Chinese Patent Application 201,511,015,059, 31 December 2015.

16. Young, K.; Chang, S.; Lin, X. C14 Laves phase metal hydride alloys for Ni/MH batteries applications. Batteries 2017, 3, 27. [CrossRef]

17. Matiland, T.; Sitzman, S. Electron backscatter diffraction (EBSD) technique and materials characterizations examples. In Scanning Microscopy for Nanotechnology Techniques and Applications; Zhou, W., Wang, Z.L., Eds.; Springer: New York, NY, USA, 2007.

18. Young, K.; Ouchi, T.; Liu, Y.; Reichman, B.; Mays, W.; Fetcenko, M.A. Structural and electrochemical properties of $\mathrm{Ti}_{x} \mathrm{Zr}_{7-\mathrm{x}} \mathrm{Ni}_{10}$. J. Alloy. Compd. 2009, 480, 521-528. [CrossRef]

19. Liu, Y.; Young, K. Microstructure investigation on metal hydride alloys by electron backscatter diffraction technique. Batteries 2016, 2, 26. [CrossRef]

20. Shen, H.; Young, K.; Meng, T.; Bendersky, L.A. Clean grain boundary found in C14/body-center-cubic multi-phase metal hydride alloys. Batteries 2016, 2, 22. [CrossRef]

21. Liu, J.; Han, S.; Li, Y.; Zhang, L.; Zhao, Y.; Yang, S. Phase structures and electrochemical properties of $\mathrm{La}-\mathrm{Mg}-\mathrm{Ni}$-based hydrogen storage alloys with superlattice structure. Int. J. Hydrogen Energy 2016, 41, 20261-20275. [CrossRef]

22. Buschow, K.H.; Van Mal, H.H. Phase relations and hydrogen absorption in the lanthanum-nickel system. J. Less Common Met. 1972, 29, 203-210. [CrossRef]

23. Young, K.; Nei, J. The current status of hydrogen storage alloy development for electrochemical applications. Materials 2013, 6, 4574-4608. [CrossRef] [PubMed]

24. Chang, S.; Young, K.-H.; Nei, J.; Fierro, C. Reviews on the US Patents regarding nickel/metal hydride batteries. Batteries 2016, 2, 10. [CrossRef]

25. Young, K.; Ouchi, T.; Nei, J.; Yasuoka, S. Fe-substitution for Ni in misch metal-based superlattice hydrogen absorbing alloys-Part 1. Structural, hydrogen storage, and electrochemical properties. Batteries 2016, 2, 34. [CrossRef]

26. Wright, S.I.; Nowell, M.M.; Field, D.P. A review of strain analysis using electron backscatter diffraction. Microsc. Microanal. 2011, 17, 316-329. [CrossRef] [PubMed]

27. Winkelmann, A. Dynamical effects of anisotropic inelastic scattering in electron backscatter diffraction. Ultramicroscopy 2008, 108, 1546-1550. [CrossRef] [PubMed]

28. Keller, R.R.; Roshko, A.; Geiss, R.H.; Bertness, K.A.; Quinn, T.P. EBSD measurement of strains in GaAs due to oxidation of buried AlGaAs layers. Microelecron. Eng. 2004, 75, 96-102. [CrossRef]

(C) 2017 by the authors. Licensee MDPI, Basel, Switzerland. This article is an open access article distributed under the terms and conditions of the Creative Commons Attribution (CC BY) license (http:/ / creativecommons.org/licenses/by/4.0/). 